Theories \& Applications, the International Edition

Printed Version: (ISSN 2090-5262)

Online Version: (ISSN 2090-5270)

November 2013, Volume 3, No. 3 Pages (137 - 153)

\title{
Effect of the Physical Effort Levels on the Angular Impact Kinematics When Performing Kicking Accuracy With Instep in the Soccer Junior
}

\author{
Abo Abda. Hassan*, Elagamy. Omaima**, AL-Mangor. Abdulkareem***
}

\begin{abstract}
Kicking in soccer with accuracy is influenced with a group of factors. It is noted the paucity of the scientific studies which addressed other variables related to the effect of the physical effort levels on the kicking performance. Most of the treatments have done on kicking from stationary situations without paying attention to study kicking performance skill in the moving play situations a simulation to what occurring during the actual practice(the game). Therefore the purpose of this study was to know the effect of the different physical effort levels on the change in the angular kinematics impact when performing kick accuracy of a moving ball with front instep of the foot in soccer players. $(N=10)$ junior soccer players (varsity players) age: $16.8 \pm 0.55$ years, height 173.4 $\pm 7.41 \mathrm{~cm}$., weight $66.7 \pm 8.65 \mathrm{~kg}$. have completed five levels of physical effort according to Hoff Test(10 min. for each level). In this test the levels were determined based on: running distance(m.), lactic acid concentration in blood (mmol $/ \mathrm{L})$, heart rate during the test and on kicking performance( $b$ /min.) and perceiving exertion scale(deg.). The best trial(the most accurate) from four front instep kick trials of a complex skill ending with shooting were analysed by using Motion Track program 3.D. and by using 3 camera $(25 \mathrm{HZ})$. The first camera to the side of the player, the second to the side of the goal, the third behind the player and in front of the goal. The first and third cameras were used to analyze the angular kinematic variables of the impact phase(impact between foot and ball). Second and third cameras to define accuracy level. The results revealed that there were statistical significant differences $(P<0.05)$ between the different physical effort levels in the kinematic variables related to the angular distance variables: angle of knee and hip joints of both kicking and supporting legs and ball release angle and angle of the knee extension and hip flexion of the kicking leg, also to know the kinematic variables relevant to the angular velocity of the variable of: angular velocity of foot and shank of both kicking and supporting legs and ball velocity. It was found a great effect size of these variables in favor of the low and moderate physical effort levels comparing to the high sub-maximum and maximum levels. The present results suggested that Hoff Test protocol which simulate the actual practice(the game)lead to an impairment of kicking performance in soccer because there were functional and physiological changes which in turn changed kicking performance mechanics in soccer.
\end{abstract}

\section{Introduction}

$\mathrm{P}$ hysical performance during actual practice is considered a complex phenomena, but it

\footnotetext{
* Prof. of Soccer training. dep. of athletics training, faculty of Physical Education for Men. Alex. University

** Prof. of Biomechanics. dep. of Physical Education principles, faculty of Physical Education for Men, Alex. University.

*** Scholar in the program of khadem EL-haramain Elsharefain of the expatriate scholarship program of the higher education in Saudi Arabia. Ph.D. soccer training, Dep. Of athletics training, faculty of physical education for men. Alex. University.
}

represents the final product of the training processes (Stolen et al., 2005 [73]). Training quality in all sports in general and which depends on the endurance activity on amount and kind of the physical effort which is performed and on number and kind of the information which is giving to the player during training. It is noted that most of the coaches when learning and developing the sports skills on the optimum performance of the skill without taking into consideration the players situation when performing, and to what extent this 
simulate what is done during the actual practice(Reilly., 1996b [59]). Therefore, knowing the kinematic changes on performing the sports skills during the physical effort is an assistant factor for the caches and players in understanding and developing the training methods and organize the training processes concerning the players to prepare them skillfully and tactically, (Kellis \& Katis., 2007 [31] ).

The exerted physical effort during the actual practice of the athletics, which depend on endurance activities in general lead to a biomechanical changes in the skillful performances. As the scientific research results which has conducted to know the effect of the physical effort on the skillful performance level in basketball, ice hockey, handball and volleyball has indicated to the reduction in the kinematic variables related to the skillful performance of these events as a result of exhaustion (the maximum physical effort) (Uygur et al., 2010[76]; Chen et al., 2005[15]; Marino \& Drouin., 2000[42]; Bacik \& Krol \& Vaverka., 2000[7]; Sardinha \& Zebas., 1986[66]). Also, the scientific studies which conducted to know the effect of the physical effort on the body lower limb functions during running vertical jump or running, events have revealed that there is reduction in the kinematic variables as a result of the maximum body effort(Hanley \& Smith., 2009[27]; Rodacki et al., 2002[64]; Rodacki et al., 2001[65]; Bruggeman., 1996[13]).

Concerning soccer game and which is one of the world wide spreading sports either as a practice or watching(FIFA., 2000[25]), there are many basic skills to perform it as kicking skill is the most important one as it is the most important means used in achieving goals(achievement criteria in soccer game)(Pilar \& David., 2011[54]). Therefore it is interesting to be a focus of coaches and players. Also kicking skill has a direct contact between the ball and the kicking foot. The tool being kicked(Soccer) could be in a stationary position on the ground or moving in the air(Shan \& Zhang., 2011[69]; Egan \& Vwerheul \& Savelsbergh., 2007[20]). The contact point between the ball and the site of the foot is divided into 4 common approaches: front instep, Inner instep, Outer instep and inside(soleus) of the foot (Abo-
Abda., 1981[2]). All these methods are used to achieve the most important production: (To reach the ball to the goal), some of these methods achieving more success than the other. Front instep kicking is the most used with high frequencies in games comparing to other methods which have less probability to be successful (AL-Mangor., 2009[4]).

Kicking skill is divided into three important phases(Preliminary, Main and Final) these phases are divided according to the biomechanical science as it is one skill with three phases(Bloomfield et al., 2007[12]). Results of the biomechanical studies in the last decades have indicated to a various forms in dealing with kick characteristic in each phase, and a great attention was paid to the main phase. The moment of impact when kicking with foot because of its effect and value in achieving the optimum production either kicking with accuracy, kicking with force or kicking with velocity of the ball (Kellis \& Katis., 2007[31]; Lees \& Nolan., 1998[40]).

Kicking is considered one of the skills with multiphase's movements where movement of body links(parts) are with in connected system. It is characterized with a group of angular movements of many mechanical factors of the lower limb (Goktepe et al., 2008[26]). The most important angular kinematic variables in the main stage of front instep kick skill is concerning with impact which involves variables of: distance, angular velocity of joints and lower body segments (Foot, Knee, Hip).

The kinematic factors are influenced with the purpose of executing foot kick, as kicking with accuracy is different from kicking with force(Kellis \& Katis., 2007[31]). Kicking with accuracy is affected with a group of factors in the phase of performing kicking skill(Barbieri et al., 2010[10]; Massoumi \& Shahbazi., 2006[43]). It was noted the paucity of the studies which dealt with other factors related to the main phase of performance and its effect on performing kicking with accuracy. Most studies have focused on kicking from stationary situations without paying attention to kicking skill with accuracy in different physical effort levels, as a simulation to what is done during the actual practice(The game) or the differences in the performance level in the elite players in 
performing kicking with accuracy and how to manage this in the training programmes(Lees et al., 2010[38]; Kellis \& Katis., 2007[31]).

Soccer required a significant physical effort range from moderate to higher intensity most of the actual practice periods(The game), as the body effort affects physiologically on the body systems starting from cardiovascular system, and neuromuscular system and ending with the systems which supply energy and control the body temprature (Reilly., 1997[60]). For the biomechanical factors, the studies of the body effort effect on performing the technical skills were not getting enough attention in the last decades(Lees et al., 2010[38]; Kellis \& Katis., 2007[31]), as most of these studies have dealt with kicking skill but in sub-maximum body effort and in stationary play situations. Few modern studies have dealt with the maximum body effort(Exhaustion) on performing kicking skill with force. It was noted that these studies did not examine the effect of the body effort on the kinematic variables related to kicking with accuracy, but it was focused on using only maximum body effort with using ball(Not simulating the actual practice) without examining the effect of different body effort levels as it occurs during the actual practice(The game) of soccer. In addition, monitor kicking performance of moving ball with mechanical accuracy of the players during the actual practice in the different physical effort levels is very important to direct training programmes and contribute to scoring goals, this was recommended by many researchers interested in soccer(Shan \& Zhang., 2011[69]; Lees et al., 2010[38]; Sterzing., 2010[71]; Reilly \& Korkuzuz., 2009[62]; Dargiewicz \& Erdmann., 2007[16]; Bloomfield et al., 2007[12]; Mohr et al., 2005[50]; Stolen et al., 2005 [73]; Ekblom., 1994[21]; Bangsbo et al., 1991[11]; Abo-Abda., 1981[2]). All these studies reported that there no benefit of studying variables and body effort levels during the actual practice (The game) in soccer without field and applying benefits. Therefore the purpose of this study was to examine the effect of different body effort levels (Low, Moderate, High, Sub-maximum, Maximum) on the change in angular kinematic impact when performing front instep kick with accuracy in elite and junior soccer players.

\section{The Study Procedures}

\section{The sample:}

$(\mathrm{N}=10)$ players were chosen intentionally from Saudi Arabia varsity players from juniors in soccer 2009/2010. Those who have injuries, taking medicine, in rehabilitation stage or not physically fit from the medical records of the varsity administration were eliminated. Regular consent was taken from the youth care headquarter in Saudi Arabia in order to conduct the study. Written consent of the players were taken to share in this study. During conducting the $\operatorname{study}(\mathrm{N}=3)$ players were eliminated either they were not attending regularly, not commitment to the study procedures or the extracted data in the procedures were not sound (measurements were not achieving the required physical effort) and they replaced with $(\mathrm{N}=3)$ other players. The subjects age: $16.8 \pm 0.55$ years, height: $173.4 \pm 7.14 \mathrm{~cm}$., weight: 66.7 $\pm 8.65 \mathrm{~kg}$., BMI: $22.13 \pm 1.98 \mathrm{Kg} / \mathrm{m} 2$, Each had: $3.1 \pm 0.87$ years of soccer training. All the players were right footed.

\section{Tools of collecting data:}

The sample descriptive data was computed: computing age, training age, height, weight and BMI (Reilly., 1996a[58]). Also, heart beat (b/min.) was measured distance by using (vantage-XL)device through physical effort levels (Low, Moderate, High, Sub-maximum, Maximum) and during kick performance (Kylie et al., 2006[36]; Stolen et al., 2005 [73]; ALHazzaa et al., 1995[3]). In addition, to each level of physical effort levels which were defined according to heart beat rate from heart beat reserves(Stolen et al., 2005 [73]; Reilly., 1996a[58]). Also lactic acid concentration in blood was measured $(\mathrm{mmol} / \mathrm{L})$ after finishing each level of physical effort and kicking test by using(Lactate pro) device (Kylie et al., 2006[36]; Kellis et al., 2006 [32]). Physical effort was performed by using similar procedures of Hoff Track Test repeated 5 times in different physical effort levels based on heart rate(Stolen et al., 2005 [73]; Hoff \& et al., 2002[28]). After each physical effort test kicking test was conducted until finishing the last physical effort level. Time of running with ball (min/ sec.)was computed by using stop watch. Running distance (m.)was computed 
through counting number of rotations and stopping station in each physical effort level. Also perceived exertion (deg.)was measured by using Borg's scale before performing kicking test and after performing each physical effort test on Hoff Track and by using a guiding board displaying the degrees of the physical effort sensing in its different levels (Kylie et al., 2006[36]; Kellis et al., 2006 [32]). Accuracy level(deg.) was measured by using a complex skillful performance test ending with front instep kick accuracy level was evaluated in the upper right of the goal by using back and side cameras (deg.)(Scurr \& Hall., 2009[68]). The best front instep kick trial(the most accurate) was chosen at each physical effort level(Low, Moderate, High, Sub-maximum, Maximum).

Finally, motor analysis of front instep kick was made through capturing four kicking trials for each player after each physical effort level (Low, Moderate, High, Sub-maximum, Maximum). Three dimensions system was used by using two video camera Panasonic, 25HZ. (Fig. 1). Showed the cameras position and measurements of kicking test. One trial(The most accurate one) was analysed after performing each physical effort for all the players(Total trials $=50$ )through Motion Track program and by the assistance of specialists from EL-Shora Technological Company.

Figure (1)

Schematic model of the form, places and tools of kicking foot test.

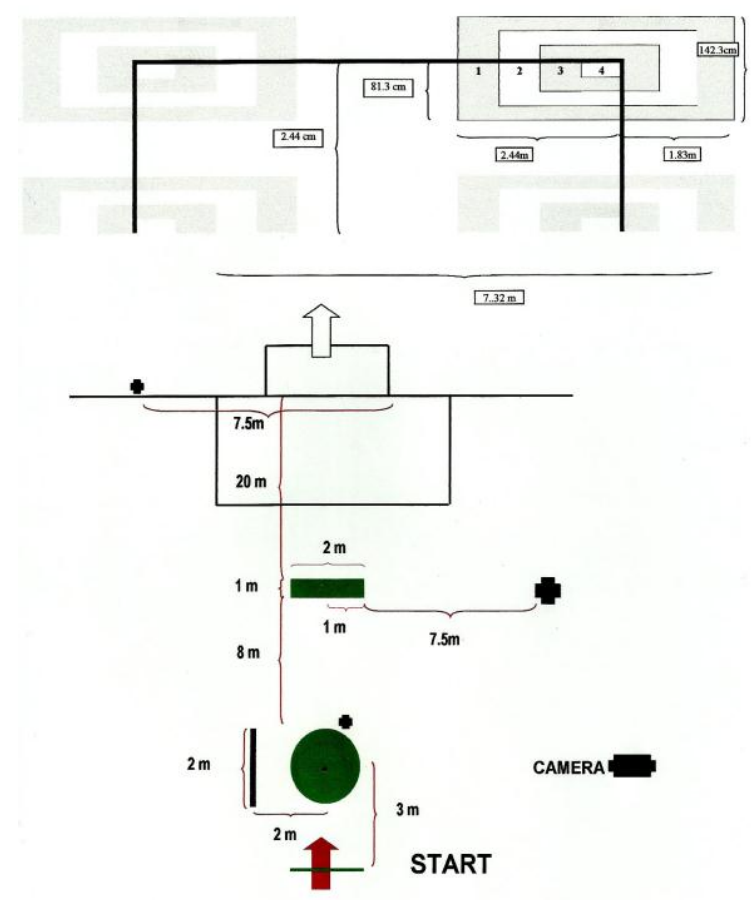

The variables in the impact phase was computed through the sum of the different directions (X,Y,Z,ZY,ZY,ZX,ZYX), after defining the angular kinematic variables of the impact phase and which include: angular distance variables(deg.)of body joints (Foot, Knee, Hip) of both kicking and supporting legs and trunk tilt, in addition to the knee extension and hip flexion angle of the kicking leg, which means the change rate in the angle of knee and hip jointing of the kicking leg as it begins with the maximum angle at the end of back swing and the beginning of the forward swing and until the impact phase, finally, ball release angle. Also, angular velocity variables(deg/ sec.) of body joint(Foot, Shank, Thigh)of both kicking and supporting legs. Ball velocity was computed based on the average of three frames followed the impact phase.

\section{The pilot studies:}

The pilot studies were done from March to April 2010. The purpose of this study was to define Hoff Track measurements, to make sure of the balls validity an its accordance with balls authorized from FIFA, validity of physiological devices and measurements, place for making pictures, how to compute the physiological 
variables, kinematic variables related to front instep kick, how to compute accuracy level mechanically in the different physical effort levels, define places to put the cameras, suitable angles, distances required for clear photos, movements domain inside the cameras, places of putting the guiding marks of the trial numbers and the range of its clearance, define photos place and zone, places and responsibilities of the examiners(assistants), compute the total time of performing the physiological and skillful performance. In addition to train the basic study sample on how to control heart beats in each different physical effort level when performing the physical effort and during foot kick.

\section{The basic studies:}

The researcher with the help of the specialists and workers in the biomechanical laboratories and physical effort physiology at the faculty of sports science and physical effort in King Saud University, Saudi Arabia has conducted the basic study on the participants. (Fig. 2). Shows schematic diagram illustrating the physical effort test, measurements of the basic study.

Figure (2)

Schematic diagram of the basic study procedures.

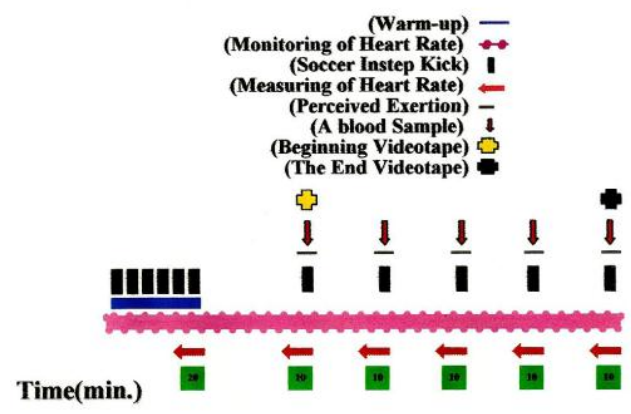

\section{Statistical treatment:}

This was done by using SPSS, Median, Standard deviation, Analysis of Variance, $\operatorname{LSD}(\mathrm{P}=0.05)$, Least Significant Difference, Effect Size(r2), the following criterion representing the amount of effect $\operatorname{size}(0.01=$ small, $0.06=$ medium, $0.15=$ large $)$.

\section{Results and discussion:}

Study results and its discussion will be in three cores through studying physiological variables and level of accuracy, distance and velocity variables related to the kinematic angular of impact phase when performing kick accuracy with front instep in the soccer junior players. Following a detail explanation of the present study results:

The physiological variables and level of accuracy:

The present study used Hoff Test to measure the different physical effort levels which validated before, as it considered one of the modern tests, and the most simulated during the actual practice(The game) of soccer(Stolen et al., 2005 [73]; Hoff et al., 2002[28]). The results in (Table. 1). indicated that there were no statistical difference $(\mathrm{P}<0.05)$ between the physical effort levels(Low, Moderate, High, Sub-maximum, Maximum) in the medians of the running time(min. sec.) in Hoff Test, measuring accuracy level in front instep kick test, this giving an indication to the sound procedures related to the present study which conditioned fixed time to perform running, kicking with accuracy in each of the different physical effort levels.

The results, also showed a differences between the physical effort levels(Low, Moderate, High, Sub-maximum, Maximum) in the medians of the running distance $(\mathrm{m}$.$) , heart beat rate during$ Hoff Test(beat $/ \mathrm{min}$.) perceiving exertion (deg.), heart beat rate when kicking(beat min.), concentration of lactic acid in blood $(\mathrm{mmol} / \mathrm{L})$ as LSD $(\mathrm{P}<0.05)$ between all levels. When looking to the total distance results which was covered in the present Hoff Test $(9850 \mathrm{~m}$.) which is approximately in accordance with the distance covered by the soccer players during the actual practice(The game)(Veale et al., 2007[77]; Misuta et al., 2006 [47]; Mohr et al., 2003[49]).

Moreover, heart beat rate values which have been noticed in this study were similar to what we have mentioned during the actual practice(The game) in soccer (Jesper et al., 2004[29]; Capranica et al., 2001 [14]). Similary, lactic acid concentration in blood was comparable to what mentioned in studies of soccer competition games of the junior where the first half values were higher than the second half,(Mohr et al., 2003[49]; Capranica et al., 2001 [14]). In addition, perceiving exertion 
values have increased statistically significant with the increasing the physical effort levels from low to the maximum. Results of this scale in different physical effort levels with scientific studies conducting in different. Events such as water polo (Kylie et al., 2006[36])and in soccer(Kellis et al., 2006 [32]).

The physiological variable results and accuracy level confirm the sound of the procedures, this has a great importance to test the basic hypothesis in this study. Also it is probable that changes may occur to stimulate the physical effort levels in a small amount in the kinematic of kick performance which may not be clear for some reasons because of the good physical fitness of the participants.

\section{Angular distance variables:}

Table.(2) indicated that the significance of the differences between physical effort levels(Low, Moderate, High, Sub-maximum, Maximum)in medians of the ball release angle, knee and hip joints angle of the kick leg, angle of knee extension and hip flexion of kick leg, knee and hip joints angle of the support leg as most of it tend to be in favor of the low and moderate physical effort comparing to high, submaximum and maximum.

Table.(1)

Significant Differences Between the Physical Effort Levels(Low, Moderate, High, Sub-maximum, Maximum) in The Physiological Variables and Accuracy Level by using LSD Test $(N=10)$.

\begin{tabular}{|c|c|c|c|c|c|}
\hline \multirow{2}{*}{ Variables } & \multicolumn{5}{|c|}{ Physical Effort Levels ( Mean \pm SD ) } \\
\hline & Low & Moderate & High & Sub-maximum & Maximum \\
\hline Running Time(min. sec.) & $9.81 \pm 0.3$ & $9.8 \pm 0.26$ & $9.81 \pm 0.27$ & $9.8 \pm 0.25$ & $9.81 \pm 0.28$ \\
\hline Running Distance(m.) & $\begin{array}{c}1361.7 \\
\pm 25.9\end{array}$ & $\begin{array}{c}1573 \\
\pm 24.3^{*}\end{array}$ & $\begin{array}{c}1914.1 \\
\pm 30.3 * \#\end{array}$ & $\begin{array}{c}2263.6 \pm 31.9 * \\
\# \mathrm{a}\end{array}$ & $\begin{array}{c}2737.6 \pm 66.8^{*} \\
\# \text { a }\end{array}$ \\
\hline \multicolumn{6}{|c|}{ Heart Rate(b/min.) } \\
\hline During Hoff Test & $\begin{array}{l}128.7 \\
\pm 4.7\end{array}$ & $\begin{array}{c}144.1 \pm \\
4.7 *\end{array}$ & $\begin{array}{c}161.5 \pm 2.4^{*} \\
\#\end{array}$ & $\begin{array}{c}176.5 \pm 4.3 * \# \\
a\end{array}$ & $\begin{array}{c}189.2 \pm 5.2 * \# \\
a \cdot\end{array}$ \\
\hline At kicking & $128.6 \pm 2.7$ & $\begin{array}{c}142.9 \pm \\
3.9 *\end{array}$ & $\begin{array}{c}159.8 \pm 1.5^{*} \\
\#\end{array}$ & $176 \pm 2.7 * \#$ & $\begin{array}{c}194 \pm 2.5 * \# \text { a } \\
\bullet\end{array}$ \\
\hline Perceiving Effort(deg.) & $10.6 \pm 1.3$ & $\begin{array}{c}12.8 \\
\pm 1.03 * \\
\end{array}$ & $\begin{array}{c}15.1 \pm 0.74^{*} \\
\#\end{array}$ & $\begin{array}{c}17.2 \pm 0.79 * \# \\
a\end{array}$ & $\begin{array}{c}19.5 \pm 0.71 * \# \\
\not \bullet \bullet\end{array}$ \\
\hline $\operatorname{Lactic} \operatorname{Acid}(\mathrm{m} \operatorname{mol} / \mathrm{L})$ & $2.6 \pm 0.57$ & $\begin{array}{c}4.1 \\
\pm 0.33 *\end{array}$ & $\begin{array}{c}6.4 \pm 0.67 * \\
\#\end{array}$ & $\begin{array}{c}10.9 \pm 0.49 * \# \\
a\end{array}$ & $\begin{array}{c}13.4 \pm 0.61 * \# \\
a \bullet\end{array}$ \\
\hline Accuracy Level(deg.) & $3 \pm 1.1$ & $3.4 \pm 0.7$ & $2.5 \pm 1.2$ & $2.3 \pm 0.82$ & $2.4 \pm 0.97$ \\
\hline
\end{tabular}

* Different from low exertion. \# Different from moderate exertion. aDifferent from high exertion. $\bullet$ Different from sub-maximum exertion. 
Table (2)

Significant Differences Between The Physical Effort Levels(Low, Moderate, High, Sub-maximum, Maximum) in The Angular Distance Variables by Using LSD Test $(N=10)$.

\begin{tabular}{|c|c|c|c|c|c|}
\hline \multirow{2}{*}{ Variables } & \multicolumn{5}{|c|}{ Physical Effort Levels( Mean \pm SD ) } \\
\hline & Low & Moderate & High & Sub-maximum & Maximum \\
\hline Ball Release Angle(deg.) & $41.01 \pm 4$ & $\begin{array}{c}40.97 \pm \\
4.7\end{array}$ & $\begin{array}{c}49.9 \\
\pm 7.1 * \#\end{array}$ & $49.1 \pm 7.8^{* \#}$ & $50.4 \pm 9.5 * \#$ \\
\hline \multicolumn{6}{|c|}{ Joints Angle of Kicking Leg(deg.) } \\
\hline Ankle & $\begin{array}{c}92.9 \\
\pm 12.7\end{array}$ & $\begin{array}{c}85.1 \\
\pm 12.5\end{array}$ & $92.6 \pm 13.6$ & $90.1 \pm 15.4$ & $94.3 \pm 13.6$ \\
\hline Knee & $\begin{array}{r}125.2 \\
\pm 10.3 \\
\end{array}$ & $\begin{array}{l}125.8 \\
\pm 10.1 \\
\end{array}$ & $\begin{array}{c}136.2 \\
\pm 14.1 * \\
\end{array}$ & $136.2 \pm 10.8^{*}$ & $\begin{array}{c}143.9 \\
\pm 12.9 * \# \\
\end{array}$ \\
\hline Hip & $\begin{array}{l}130.1 \\
\pm 6.2\end{array}$ & $\begin{array}{c}133.5 \\
\pm 8.2\end{array}$ & $\begin{array}{l}127.9 \\
\pm 4.2 \#\end{array}$ & $126.7 \pm 3.7 \#$ & $125 \pm 5.1$ *\# \\
\hline \multicolumn{6}{|c|}{ Joints Angle of Support Leg(deg.) } \\
\hline Ankle & $94.7 \pm 8.8$ & $92.7 \pm 8.4$ & $93.3 \pm 11.2$ & $93.7 \pm 8.01$ & $96.6 \pm 8.8$ \\
\hline Knee & $\begin{array}{c}129.8 \pm \\
6.4\end{array}$ & $131.3 \pm 3.2$ & $135.01 \pm 6$ & $139.3 \pm 8.8$ *\# & $\begin{array}{c}144.5 \pm 8.3^{*} \\
\# \mathrm{a}\end{array}$ \\
\hline Hip & $\begin{array}{c}133.9 \pm \\
8.3\end{array}$ & $\begin{array}{l}141.8 \\
\pm 4.3 * \\
\end{array}$ & $\begin{array}{l}141.9 \\
\pm 9.3 * \\
\end{array}$ & $141.3 \pm 10.6^{*}$ & $144.9 \pm 6.8 *$ \\
\hline Knee Extension (deg.) & $\begin{array}{c}56.6 \\
\pm 12.1 \\
\end{array}$ & $\begin{array}{c}52.7 \\
\pm 13.6 \\
\end{array}$ & $63.6 \pm 14.1$ & $66.8 \pm 9.3 \#$ & $\begin{array}{c}71.8 \\
\pm 13.01 \text { *\# } \\
\end{array}$ \\
\hline Hip Flexion(deg.) & $25.2 \pm 6.1$ & $35.2 \pm 6$ & $\begin{array}{l}41.2 \pm \\
5.8 * \#\end{array}$ & $43.1 \pm 5.7$ *\# & $40.6 \pm 6.6$ \\
\hline Trunk Tilt(deg.) & $49.6 \pm 5.7$ & $48.1 \pm 6.7$ & $48.97 \pm 7.4$ & $49.7 \pm 7.7$ & $54.8 \pm 13.2$ \\
\hline
\end{tabular}

* Different from low exertion. \# Different from moderate exertion. oDifferent from high exertion. • Different from sub-maximum exertion.

This indicated that physical effort levels an is effective factor on some angular distance variables and one important factor affect the technical performance of front instep kick. In addition that it is a significant factor in many of the influences on the kick performance (Barbieri et al.,2010[10]). Therefore it is not interesting that these variables are affected as a result of the different physical effort levels when performing front instep kick in soccer. On the basis of these results, the main research hypothesis of this study is supported.

These results were in accordance to the scientific studies conducted in the different sports and its results revealed the effect of the physical effort effect on some angular distance variables of body parts and links when performing kick skill in Australian rules football(Rugby) (Evan et al.,2011[23]). Also when perform ice skating skill in ice hockey(Marino \& Drouin., 2000[42]). Also when performing spike skill in volleyball(Sardinha \& Zebas., 1986[66]). In addition, the results of the present study are in accordance with the scientific study results in soccer which indicated to the effect of the physical exhaustion(maximum physical effort) on the angular distance variables performing front instep kick in running approach comparing to other kinds of approach (Kilani \& Oddtallah., 2008[34]). Also, revealed an effect of the physical exhaustion (maximum physical effort)on the knee joint of kicking leg when performing front instep kick which is characterized with force in soccer (Apriantono et al., 2004[6]). Also, it was in accordance with what was reported by(Lees., 2009[37]) about the importance of the angular change of the knee and hip joints when performing foot kick as it is related to various aspects and which was confirmed by (Baljinder et al., 2011[9]) that there is a clear effect of the distance kick on the knee and hip joint angle, also, results of the study of(Matt et al., 2009[45]) which confirmed the occurrence of change in knee joint during running in soccer game as a result of the increased in physical effort, this means the importance of the kinematic variables when studying any effect on kick performance.

To confirm the former, (Table. 3). showed a positive statistical differences relation $(\mathrm{P}<0.05)$ between the physical effort levels (low, moderate, high, sub-maximum, maximum) and medians of the ball release angle, knee joint 
angle of the kick leg, angle of knee extension and hip flexion of the kick leg and the knee and hip joints of the supporting leg. When looking at the ball release angle values it is noticed that it were near to each other in the low physical effort level (41.01 deg.) the moderate (40.94 deg.) and markedly different comparing to the high physical effort (49.86 deg.) the submaximum (48.08 deg.) or the maximum (50.44 deg.). This show an indication that the increase in the physical effort levels from low to maximum lead to increase in the ball release angle which is in accordance with scientific studies which used other various influences on the release angle such as different approach angles' (Sasa et al., 2010[67]), effect of the movable ball force(Massoumi \& Shahbazi., 2006[43])or the effect of the kick path and form (high, low) (Prassas et al., 1990[55]).

Table (3)

Amount of change ' $B$ ' and correlation of coefficient ' $R$ ' and values ' $F$ ' and significance level and effect size of the interrelation between the physical effort levels(Low, Moderate, High, Sub-maximum, Maximum) and the angular distance variables in concern $(N=10)$.

\begin{tabular}{|c|c|c|c|c|c|c|}
\hline Variables & $\mathrm{B}$ & $\mathrm{R}$ & $\mathrm{F}$ & Sig. & Effect Size & Ranking \\
\hline Ball Release Angle(deg.) & 2.7 & 0.49 & $14.7^{*}$ & 0.00 & $0.24 \ddagger$ & 3 \\
\hline Joints Angle of Kicking Leg(deg.) \\
\hline Ankle & 0.8 & 0.8 & 0.3 & 0.57 & 0.006 & 10 \\
\hline Knee & 4.8 & 0.51 & $17.03^{*}$ & 0.00 & $0.26 \ddagger$ & 2 \\
\hline Hip & 1.7 & $0.39-$ & $8.73^{*}$ & 0.005 & $0.15 \ddagger$ & 6 \\
\hline Joints Angle of Support Leg(deg.) \\
\hline Ankle & 0.5 & 0.8 & 0.31 & 0.6 & 0.007 & 9 \\
\hline Knee & 3.7 & 0.63 & $31.3^{*}$ & 0.00 & $0.40 \ddagger$ & 1 \\
\hline Hip & 2.2 & 0.36 & $6.9^{*}$ & 0.01 & $0.13 \dagger$ & 7 \\
\hline Hip Flexion(deg.) & 1.9 & 0.40 & $9.1^{*}$ & 0.004 & $0.16 \ddagger$ & 5 \\
\hline Trunk Tilt(deg.) & 1.2 & 0.20 & 1.96 & 0.17 & 0.04 & 8 \\
\hline
\end{tabular}

* P<0.05 * effect high. + effect moderate.

For the knee joint angle of the kick leg it is approximate at the low level of physical effort (125.22 deg.), at the moderate level (125.76 deg.) and markedly different in the others: the high level (144.3 deg.), sub-maximum (136.15 deg.) and maximum level (143.92 deg.). also knee extension angle of kicking leg was approximated at the low level of the physical effort (56.61 deg.), moderate (52.74 deg.) and markedly different in the other levels the high (63.59 deg.), sub-maximum (66.82 deg.) and the maximum(71.84 deg.). This indicated to the effect of physical effort levels on knee joint angle of the kicking leg and on knee extension angle of the kicking leg which in accordance to the scientific study results which has used other influences (Mohammed et al.,2011[48]; Barbieri et al.,2010[10]; Prassas et al., 1990[55]). This giving an indication that knee joint extension of the kicking leg is greater in the higher levels of the physical effort (high, sub-maximum, maximum)comparing to the lower physical effort levels (low, moderate), which means it is necessary to accompany this increase in the angular velocity of the lower body links according to the results of the study of (Levanon \& Dapena.,1998[41]), which indicated that the increase of knee joint extension of the kicking leg from the beginning of the front swinging phase until the impact phase is an important indicator to increase the velocity to the lower body links of the kicking leg in the impact phase, which considered an important factor and the most contributing to the quality of the front instep kick performance. Although this is in contrast to the present study results which revealed a reduction in the angular velocity of the lower body links in the higher physical effort levels (high, sub-maximum, maximum) in spite of the increase of the knee joint extension of the kicking leg. But the study results of (Nunome et al.,2002[51]), not emphasized on the importance of the knee joint extension of the kicking leg in increasing the angular velocity of the lower body segments of the kicking leg in the impact phase, and the greater role is due to the importance of the outer rotation of the hip joint of the kicking leg.

Also the present study results are in accordance with the results of the study of (Egan \& Verheul 
\& Savelsbergh.,2007[20]), which revealed differences between kicking stationary ball and movable ball in the knee joint of the kicking leg and the velocity of the toes in favor of kicking the movable ball as it indicated that there is less extension of the knee joint of the kicking leg accompanied with velocity of the kicking leg toes which is larger in kicking the movable ball comparing to the stationary ball.

The researcher has suggested that the increase in the knee joint extension of the kicking leg with less increase in the higher physical effort levels to the probability that there is timing less accuracy in the movement path of the contact of the kicking leg foot with the ball in the impact phase. As the present study procedures depends on kicking the movable ball with the front instep foot therefore the mechanics of kick performance of the movable ball required higher performance of the motor perceiving and a higher level of the coordination ability which was confirmed by (Egan \& Verheul \& Savelsbergh.,2007[20]). Therefore these reasons may have influenced on performing knee joint of the kicking leg when performing front instep kick in the higher levels of the physical effort. The paucity of the scientific studies which dealt with the knee joint when performing kicking the movable ball to reinforce the importance of knowing if these is an ideal angle of the knee joint of the kicking leg to achieve a higher and ideal quality(characterized with accuracy and velocity) and help to know when the knee joint extension serves the motor path and to what extent it related to the other kinematic variables when performing front instep kick in soccer game either in the higher or lower physical effort levels.

Concerning the hip flexion angle of the kicking leg it is approximate at the low physical effort level (35.22 deg.) moderate (35.23 deg.) and markedly different in other higher levels (41.18 deg.), sub-maximum (43.07 deg.) the maximum (40.56 deg.). This means that increasing hip flexion of the kicking leg in the higher physical effort levels(high, sub-maximum, maximum) comparing to the lower physical effort levels(low, moderate) is an indicator to the effect of the physical effort levels on the hip flexion angle of the kicking leg. It is known that the angular hip movement path helping the foot of the kicking leg to reach to an ideal contact with the ball and increase the hip flexion angle with the increase of the physical effort levels is giving an indicator that there is improper timing in hip joint performance which leads to the increase in the hip flexion angle of the kicking leg. This is in accordance to the scientific study results which used different influences and its results emphasized occurring a change in hip joint angle of the kicking leg (Prassas et al., 1990[55]). Also the present results agreed with the results of the scientific studies which confirmed that the increase of the hip joint flexion of the kicking leg is considered one assistant factor to increase the velocity of the kicking toes in the impact phase(Egan \& Verheul \& Savelsbergh.,2007[20]; Nunome et al.,2002[51]; Levanon \& Dapena.,1998[41]).

Finally the results revealed that medians of the knee joint angle(129.81 deg.) hip (133.87 deg.)of the supporting leg were the least averages at the low physical effort level comparing to the other averages in the other level efforts(moderate, high, sub-maximum and maximum) the highest was at the maximum physical effort level: knee joint(144.49 deg.) hip joint(144.7 deg.)of the supporting leg comparing to the other averages in the other physical effort levels(low, moderate, high, submaximum). This means that there is an effect of physical effort levels on the angle of the knee and hip joint of the supporting leg which means the importance of studying the kinematic variables specially those related to the angular distance of the supporting leg, this is in accordance to what emphasized by(Lees et al., 2010[38]).

These results emphasized that joints and segments of the lower limb of both kicking and supporting legs is a continuum to serve the main motor duty. Although the flexion or extension of knee and hip joints of the supporting leg is not important to the quality and accuracy of front instep kicking(Dichiera et al., 2006[17]), it is importance is clear in the present study with the increase of the physical effort levels. These results draw our attention to follow up and monitoring the changes in the kinematics of the supporting leg especially which related to the angular distance. This has emphasized in a recent study of (Abdul Hadi \& Ali., 2012[1]), 
that there is an effect of the training programmes on improving foot kicking performance through developing and promoting the motor performance of the supporting leg.

Results, also, revealed that there is a negative statistical significant relation $(\mathrm{P}=0.05)$ between the physical effort levels (low, moderate, high, sub-maximum, maximum) and the hip joint angle of the kicking leg. This is an indicator that the increasing physical effort level from low to maximum leads to reduction in hip joint angle of the kicking leg that means delay in hip joint flexion which is seen only in impact phase and emphasize that there is improper timing in the lower body joints and segments performance with the increase of the physical effort level from low to maximum and the motor path is not done ideally concerning the beginning and ending of the hip joint flexion.

The results revealed the amount of change between the physical effort levels (low, moderate, high, sub-maximum, maximum) and it is more clear in the ball release angle, knee and hip joint angle of the kicking leg, angle of knee extension and hip flexion of kicking leg and angle of knee and hip angles of the supporting leg. To emphasize this, the results of effect size have indicated to a large influence of the physical effort levels(low, moderate, high, sub-maximum, maximum) on the angular distance variables of kicking knee angle, knee angle of the supporting leg followed by ball release angle, angle of knee extension of the kicking leg in addition to angle of hip flexion of the kicking leg and finally hip angle of both kicking and supporting legs.

These results are important to the skillful performance aspect represented in employing the quantitative value of the angular distance variables to improve or to maintain the skillful performance in the different physical effort levels (low, moderate, high, sub-maximum, maximum) which means that increasing the physical effort levels from low to maximum cause the reduction of the motor perception according to the movement path of the body joint and segment during kicking performance. Also on the reduction of the motor shifting between the movement of the mobile segments of the body parts. This reduction reflected on the coordination ability and on the completion of the motor perception of the amount of the muscular ability required to kick the ball towards the goal, which means acquiring the spatial perception with body movement and its parts in a large and quick way to sense with the muscular production required to kick the ball with the increase of the physical effort level which required higher degree of motor perception.

\section{The angular velocity variables:}

Table (4). revealed that the significant differences between the physical effort levels(Low, Moderate, High, Sub-maximum, Maximum) in the means of ball velocity, angular velocity of the foot and shank of the kicking and supporting legs most of it in favor of the low and moderate physical effort comparing to the other physical effort levels the high, sub-maximum or maximum. This means that there is an effect of the physical effort with its different levels on some angular velocity variables when performing front instep kick in soccer. These results are in accordance with the scientific studies done in different sports which its results revealed effect of the physical effort on some angular velocity variables when performing ice skating skill in hockey (Marino \& Drouin., 2000[42]). Also when performing kicking from jumping in handball(Bacik \& Krol \& Vaverka., 2000[7]). Also when performing spike skill in volleyball (Sardinha \& Zebas., 1986[66]).

Concerning soccer, although the paucity of the scientific studies dealt with the effect of the physical effort on performing kicking with accuracy, the present results are in accordance with the scientific studies as its results revealed that there is an effect of the physical exhaustion (maximum) on the angular velocity of the body segments when performing front instep kick with force(Kilani \& Oddtallah., 2008[34]; Kellis et al., 2006[32]; Apriantono et al., 2004[6]). Also, the present results are in agreed with what reported by(Goktepe et al., 2008[26]), the importance of the a bout angular movements of the body segments in performing the kick especially when monitoring any other effects on kicking performance. To ensure this(Katis \& Kellis., 2009[30]) have indicated that the kicking methods have its effect on the foot angular velocity. Also, Falloon et al., 2005[24] 
have indicated to the effect of the preferred leg on the angular velocity of the body segments which means that monitoring the angular velocity of the body segments when performing kick in the different physical effort has its justification.

Table (4)

Significant Differences Between The Physical Effort Levels(Low, Moderate, High, Sub-maximum, Maximum) in The Angular Velocity Variables by Using LSD Test $(N=10)$.

\begin{tabular}{|c|c|c|c|c|c|}
\hline \multirow[t]{2}{*}{ Variables } & \multicolumn{5}{|c|}{$\begin{array}{l}\text { Physical Effort Levels } \\
\quad(\text { Mean } \pm \text { SD })\end{array}$} \\
\hline & Low & Moderate & High & Sub-maximum & Maximum \\
\hline Ball Velocity(ms-1) & $22.6 \pm 3.7$ & $\begin{array}{c}19.7 \\
\pm 2.3 *\end{array}$ & $17.8 \pm 1.7^{*}$ & $17.3 \pm 1.5 * \#$ & $17 \pm 1.3 * \#$ \\
\hline \multicolumn{6}{|c|}{ Angular Velocity of Kicking Leg (deg./s-1 ) } \\
\hline Foot & $\begin{array}{l}1166.4 \\
\pm 337.6\end{array}$ & $\begin{array}{c}1085.4 \\
\pm 345\end{array}$ & $\begin{array}{c}915.6 \\
\pm 254.5^{*}\end{array}$ & $\begin{array}{c}812.5 \\
\pm 251.9^{* \#}\end{array}$ & $\begin{array}{c}694.1 \\
\pm 162.7 * \#\end{array}$ \\
\hline Shank & $\begin{array}{l}585.9 \\
\pm 98.3\end{array}$ & $\begin{array}{c}522.1 \\
\pm 106.8\end{array}$ & $\begin{array}{c}436.2 \\
\pm 62.6^{*}\end{array}$ & $415.3 \pm 82.4 * \#$ & $\begin{array}{c}395.6 \\
\pm 123.3^{* \#}\end{array}$ \\
\hline Thigh & $\begin{array}{c}35.5 \\
\pm 20.7\end{array}$ & $\begin{array}{c}25.3 \\
\pm 19.4\end{array}$ & $23.2 \pm 16.4$ & $27.1 \pm 20.4$ & $34.8 \pm 30.1$ \\
\hline \multicolumn{6}{|c|}{ Angular Velocity of Support Leg (deg./s-1 ) } \\
\hline Foot & $\begin{array}{c}38.6 \\
\pm 49.5 \\
\end{array}$ & $88.5 \pm 44$ & $\begin{array}{c}155.6 \\
\pm 136.1 *\end{array}$ & $135.6 \pm 107.1 *$ & $\begin{array}{c}147.2 \\
\pm 107.7 * \\
\end{array}$ \\
\hline Shank & $\begin{array}{c}49.5 \\
\pm 30.9 \\
\end{array}$ & $\begin{array}{c}47.3 \\
\pm 32.9 \\
\end{array}$ & $62.7 \pm 42.9$ & $90 \pm 81.7$ & $\begin{array}{c}128.8 \\
\pm 85.1 * \# \propto \\
\end{array}$ \\
\hline Thigh & $\begin{array}{c}57.6 \\
\pm 27.9\end{array}$ & $\begin{array}{c}49.4 \\
\pm 23.1\end{array}$ & $46.2 \pm 25.4$ & $53.9 \pm 33$ & $76.9 \pm 56.5$ \\
\hline
\end{tabular}

* Different from low exertion. \# Different from moderate exertion. $\mathrm{aDifferent}$ from high exertion. $\bullet$ Different from sub-maximum exertion.

It is clear from (Table. 5), that there is a negative statistical significant levels (Low, Moderate, High, Sub-maximum, Maximum) and ball velocity(-0.63), foot angular velocity (0.57), shank(-0.56) of the kicking leg. This indicated that increasing the physical effort level from the low to the maximum leads to reduce ball velocity, and the angular velocity of the foot and shank of the kicking leg. When looking to the ball velocity values it is noted that it is reduced gradually from the low level to maximum of the physical effort(22.57, 19.66, $17.78,17.33,16.99 \mathrm{~ms}-1)$. these values are similar to what was mentioned by(Lees et al., 2010[38]; Kellis \& Katis., 2007[31]; Shan \& Zhang., 2011[69]). Also reducing ball velocity with the increase of the physical effort is an important result. Because the ball velocity is the important biomechanical indicator to the success of kicking performance and giving an applicable indication that the physical effort levels have its effect on the kicking accuracy with front instep of the foot. Ball velocity is affected with many factors, the kinematic variables are the most important of these factors(Teshima et al., 2008[75]; Masuda et al., 2005[44]; Lees \& Nolan., 1998[40]), kicking
distance(Ball., 2009[8]), approach velocity (Andersen \& Dorge., 2009[5]; Kristensen \& Andersen., 2009[35]), skill level and maturity (Kellis \& Katis., 2007[31]), and the preferring kicking methods(Smith et al., 2009[70]), kind of the sports shoes (Sterzing et al., 2009[72]), this justify the attention of many researchers that ball velocity is a very important biomechanical indicator as a result of a group of the influences which affect the ball velocity one of it is the effect of the physical effort levels in the present study. Taking into consideration the results of the angular velocity of the foot of the kicking leg it is noted that it is reduced gradually from the low to maximum of the physical effort level(1166.4, 1085.4, 915.55, 812.49, 694.14 deg. ( s-1). Also, the angular velocity of the shank of the kicking leg is reducing gradually from the low to maximum physical effort level(585.91, 522.14, 436.19, 415.3, $395.6 \mathrm{deg}$./ s-1) these results in accordance with the results of the study of(Kellis et al., 2006[32]), which confirmed the reduction in the angular velocity of the shank of the kicking leg in the impact phase as a result of physical effort effect. There is no effect of the physical effort on the angular velocity of the thigh of the kicking leg and it is 
partially in agreement with the study results of(Lees \& Davies., 1988[39]), as it is confirmed that there is larger angular velocity in the upper of the kicking leg after performing the physical effort when performing front instep kick, this is due to the difference of physical effort test comparing to the present study, as the step test 6 min. used on a step box comparing to Hoff Test used in the present study which depends on a procedures more simulating to what is done during the actual practice in soccer game, but the results is partially in agreement with a change in the lower body segement from distal to proximal which indicated to the shift of the motor energy from the distal(thigh) to the proximal(shank and foot) when performing from instep kick in the maximum physical effort comparing to the low level of the physical effort.

Table.(5)

Amount of change ' $B$ ' and correlation of coefficient ' $R$ ' and values ' $F$ ' and significance level and effect size of the interrelation between the physical effort levels(Low, Moderate, High, Sub-maximum, Maximum) and the angular velocity variables in concern $(N=10)$.

\begin{tabular}{|c|c|c|c|c|c|c|}
\hline Variables & $\mathrm{B}$ & $\mathrm{R}$ & $\mathrm{F}$ & Sig. & Effect size & Ranking \\
\hline Ball velocity(ms-1) & 1.4 & $0.63-$ & $33.2 *$ & 0.00 & $0.41 \ddagger$ & 1 \\
\hline \multicolumn{7}{|c|}{ Angular velocity to kicking leg (deg./s-1 ) } \\
\hline Foot & 126.9 & $0.57-$ & $23.1 *$ & 0.00 & $0.33 \ddagger$ & 2 \\
\hline Shank & 45.02 & $0.56-$ & $21.6 *$ & 0.00 & $0.32 \ddagger$ & 3 \\
\hline Thigh & 0.006 & 0.00 & 0.00 & 0.99 & 0.00 & 7 \\
\hline Foot & Angular velocity to support leg (deg./s-1 ) \\
\hline Shank & 27.1 & 0.38 & 7.81 & 0.08 & $0.14 \dagger$ & 5 \\
\hline Thigh & 19.6 & 0.43 & $10.9 *$ & 0.002 & $0.19 \ddagger$ & 4 \\
\hline
\end{tabular}

$* P<0.05$ * effect high. + effect moderate

Also it is in agreement with the scientific study results which was conducted to know the effect of a group of the influences on the kinematics of performing front instep kick in soccer as the effect of increasing the number of kicking trials(Khorasani et al., 2010[33]) or the effect of the preferred method for kicking(Nunome et al., 2012[52];Meamarbashi \& Hossaini., 2010[46]) or the effect of the kicking shape(high, low trajectory)(Prassas et al., 2004[55]) or the effect of the different speed to swing the kicking leg(slow, medium, high) (Dunn \& Putnam., 1986[19]) and its results showed that the angular velocity of the foot and shank of the kicking leg was influenced in the impact phase as one important variable which must be noted when studying any effect on the kinematics of front instep kick in soccer (Kellis \& Katis., 2007[31];Dorge et al., 2002[18]) reported the importance of monitoring the minimum and maximum of the angular velocity of lower body segments when studying any influence on performing front instep kick in soccer.

Concerning the angular velocity related to support leg segments it was noted that it was less at the low physical effort level: the angular velocity of the foot(38.62 deg. / s-1) shank(49.53 deg. / s-1) of the supporting leg comparing to the other physical effort levels (moderate, high, sub-maximum, maximum), it was the highest at the maximum of the angular velocity: the foot(147.21 deg./s-1) shank(128.8 deg. / s-1) of the supporting leg comparing to the other levels(low, moderate, high, submaximum). This giving an indication to the importance of studying the kinematic variables including the angular velocity of the supporting leg, as there is a little attention from the researchers as suggested by(Lees \& Nolan., 1998[40]) and supported also by (Lees et al., 2010[38]). The researcher sees that there is an effect of the higher physical effort levels(high, sub-maximum, maximum)on the angular velocity of the foot and shank of the supporting leg and the increase in the physical effort means the increase of the burden loaded on the body which leads to a greater pressure on the supporting leg which act to keep the body balance which lead to a poor coordination in the function of body segment parts which was confirmed by(Apriantono et al., 2004[6]) that there is less coordination between body parts and segments related to the performance of front instep kick in soccer. 
The results revealed that there is a statistical significant positive relation $(\mathrm{P}<0.05)$ between the physical effort levels (low, moderate, high, sub-maximum, maximum) and the angular velocity means of the foot (0.377) and $\operatorname{shank}(0.434)$ of the supported leg, this means that the increase in the physical effort level from low to maximum leads to increase in the angular velocity of the foot and shank of the supported leg and a significanl indicator to direct the training programmes to pay attention to promote the motor trajectories of the supported leg and to concentrate on the kinematics variables in the different physical effort levels when performing foot kicking. This is in agreement with modern study results which emphasized on the importance of the kinematic variables of the supported leg especially when studying other influences and this what confirmed by(Robert et al., 2007[63]) that there is an effect of the kicking methods on the kinematic variables of the supported leg when perform kicking.

The results showed the amount of change between the physical effort levels(low, moderate, high, sub-maximum, maximum)and it is more clear in the ball velocity and angular velocity of the foot and shank of both the kicking and supporting leg. This gives an indication to the effect of the different physical effort levels of these variables. Confirming this, the effect size results showed a great effect of the physical effort levels on ball velocity and angular velocity of the foot and shank of the kicking leg followed with the angular velocity of the shank of the supproting leg. In addition to a moderate effect size of the angular velocity of the foot of the supporting leg.

From the above it can be concluded that the different physical effort levels have its effect on the ball velocity and on some angular velocity variables of both the kicking and supporting legs, and to a great extent on the ball velocity and the angular velocity of the foot and shank of the kicking leg when performing the front instep kick which required accuracy of the junior soccer players.

\section{Perspectives}

The present results showed that the increase in the physical effort levels caused a remarkable reduction in the ball velocity and the variables of the distance and the angular velocity of both the kicking and supporting leg. This indicated to the importance of monitoring the angular kinematic variables of the impact phase when performing front instep kick in the higher physical effort levels during training and trying to develop it through designing a specific programmes to develop the kicking performance in the different physical effort levels and by using the angular kinematic variable measurements of the impact phase.

The results of the present study is a continuation of the earlier suggestions of(Stone \& Oliver., 2009[74]; Weston et al., 2008[78]; Ermanno et al., 2008[22]; Rampinini et al., 2008[57]; Pain \& Harwood., 2007[53]; Reilly et al., 2006[61]; Rahnama et al., 2003[56]) that the factional and perform accuracy kick with front instep is reducing with the physical exhaustion and related closely not only to the increase of risk injuries in the muscular tissues but also the reduction in technical performance of the mechanics of kicking, as a result there is need to conduct experimental studies to know the effect of the different physical effort levels on the kinetci variables of the impact phase. It is necessary to provide more support to the coaches in soccer to direct a specific program in the training to develop kick accuracy when performing front instep kick. In addition the results of the present study retaliate the former and modern challenges(Shane \& Zhang., 2011[69]; Lees et al., 2010[38])in monitoring the kick biomechanics of a moving ball which means an impotant and significant shift in the kick biomechanics with front instep foot.

\section{References}

1. Abdul Hadi I., and Ali H.(2012): Effect of the development of explosive power, shooting accuracy and flexible thigs joint, spine on penalty kick accuracy for the students majoring in soccer in faculty of physical education. World Journal of Sport Sciences, 6: (3);228236.

2. Abo-Abda H.E.(1981): Kinematic and kinetic analysis of the soccer instep kick. University Microfilm No. ADG 81-19025. 
3. AL-Hazzaa H., AL-Refaee S., and Sulaiman M.(1995): Energy demand and fluid loss during youth soccer. In Science and Football, N. ÖHata (ed). Asian Football Confederation, Tokyo, Japan pp.310-325.

4. ALMangor A.(2009): A quantitive analysis of offensive strategies of advanced teams in professional soccer league at saudi Arabia. International Scientific Conference, 49.

5. Andersen T., and Dorge H.(2009): The influence of speed of approach and accuracy constraint on the speed of the ball in soccer kicking. Journal of medicine \& Science in Sports, 21;(1): 79-84.

6. Apriantono T., Ikegami V., Sano S., and Nunome H. (2004): Effect of leg muscle fatigue on instep soccer kick. International Symposium on Biomechanics in Sports; 22:577-579.

7. Bacik B., Krol H., and Vaverka F.(2000): The influence of a passive defender and inereasing fatigue on the kinematics of the jumpshot in team handball. International Symposium on Biomechanics in Sports;455-458.

8. Ball K.(2009): Foot interaction during kicking in Australian rules football. Science and Football VI. The proceedings of the Sixth world congress on Science and Football. 36-40.

9. Baljinder S., Parminder J., and Davinder S.(2011): The relationship of the selected biomechanical variables on the performance of kicking for distance in soccer. International Journal of Sports Science and Engineering, $5 ;(4): 225-230$.

10. Barbieri F., Gobbi L., Santiago P., and Cunha S.(2010): Performance Comparisons of the kicking of stationary and rolling balls in a futsal context. Sports Biomechanics,9(1):1-15.

11. Bangsbo J., Norregaard L., and Thorso F.(1991): Activity profile of competition soccer. Canadian Journal of Sports Science;16:110-116.

12. Bloomfield J., Polman R., and O'Donoghua P.(2007): Physical demands of different positions in FA premier league soccer. Journal of Sports Science and Medicine, 6:63-70.

13. Bruggeman G. (1996): Ineluence of fatigue on lower extremity function. International Symposium on Biomechanics in Sports; 14:2936.
14. Capranica L., Tessitore A., Guidetti L., and Figura F.(2001): Heart rate and match analysis in pre-pubesscent soccer players. Journal of Sports Sciences; 19:379-384.

15. Chen W., Lo S., Lee Y., Wang J., and Shiang T.(2005): Effects of upper extremity fatigue on basketball shooting accuracy. International Symposium on Biomechanics in Sports; 633-636.

16. Dargiewicz R., and Erdmann W.(2007): Football (soccer) players kinematics at different development levels. Part two- results and conclusions. International Symposium on Biomechanics in Sports; 25:622-625.

17. Dichiera A., Webster K., Kuilboer L., Morris M., Bach T., and Feller J.(2006): kinematic patterns associated with accuracy of the drop punt kick in Australian football. Journal of Science and Medicine in Sport, 9: 292-298.

18. Dorge H,. Bull-Andersen T,. Sorensen H,. and Simonsen E.(2002): Biomechanical differences in soccer kicking with the preferred and the non-preferred leg. Journal of Sports Sciences, 20: 293-299.

19. Dunn E., and Putnam C.(1986): Kicking speed and lower extremity kinematics. 4 International Symposium on Biomechanics in Sports, 154-160.

20. Egan C., Verheul M,. and Savelsbergh G.(2007): Effects of experience on the coordination of internally and externally timed soccer kicks. Journal of Motor Behaviour, 39;(5): 423-432.

21. Ekblom B.(1994): Football( Soccer ). Blackwell Scientific Publications.

22. Ermanno R., Francom I., Carlo C., Andrea A., Ferrari B., and Ulrik W.(2008): Effect of match-related fatigue on short-passing ability in young soccer players. Medicine \& Science in Sports \& Exercise; 40(5):934-942.

23. Evan C., Kevin B., Lucy P., Simon T Robert A., and Michael M.(2011): The effect of a game-specific short term fatigue protocol on kicking in Australian football. International Symposium on Biomechanics in Sports; 29:6972. 
24. Falloon J., Ball K., MacMahon C., and Taylor S.(2005): Coordination patterns of preferred and non-preferred kicking of the drop punt kick: a kinematic analysis of the pelvis, hip and knee. International Conference on Biomechanics in Sports.

25. FIFA (2000): Football 2000 worldwide survey. www.fifa.com.

26. Goktepe A., Karabork H., AK E., Cicek S., and korkusuz F.(2008): Kinematic analysis of penalty kick in soccer. J.Fac. Eng. Arch. Selcuk Univ., 23: (3);45-49.

27. Hanley B., and Smith L.(2009): Effects of fatigue on technique during $5 \mathrm{~km}$ road running. International Conference on Biomechanics in Sports, 29: 519-522.

28. Hoff J., WislØff U., Engen L., Kemi O., and Helgerud.(2002): Soccer specific aerobic endurance training. Br J Sports Med;36:218221.

29. Jesper S., Lone H., and Klaus K.(2004): Physiological profile and activity pattern of young soccer players during match play. Medicine \& Science in Sports \& Exercise; 36(1):168-174.

30. Katis A., and Kellis E.(2009): 3-D kiematics during instep and outstep soccer kicks in pubertal players. 14th annual ECSS Congress Oslo/Norway, abstract.

31. Kellis E., and Katis A. (2007): Biomechanial characteristics and determinants of instep soccer kick. Journal of Sports Science and Medicine; 6:154-165.

32. Kellis E., and Katis A., and Vrabas I.(2006): Effect of an intermittent exercise fatigue protocol on biomechanics of soccer kick performance. Scandinavian Journal of Medicine \& Science in Sports; 16(5):334-344.

33. Khorasani M.A., Abu Osman N., and Yusof A.(2010): Kinematics analysis: number of trials necessary to achieve performance stability during soccer instep kicking. Journal of human kinetics, 23:15-20.

34. Kilani H., and Oddtallah E.(2008): The impact of fatigue on identifying biomechanic potential soccer kicking risk factors for Jordanian junior soccer players. International Symposium on Biomechanics in Sports.
35. Kristensen L.B. and Andersen T.B(2009): Effect of approach velocity in soccer kicking. Science and Football VI. The proceedings of the Sixth world congress on Science and Football. 47-49.

36. Kylie R., Damian F., Inigo M., Shona H., David P., and Bruge A.(2006): The effects of fatigue on decision making and shooting skill performance in water polo players. Journal of Sports Sciences, 24;(8):807-815.

37. Lees A.(2009): The biomechanics of football skills. Science and Football VI. The proceedings of the Sixth world congress on Science and Football.11-18.

38. Lees A., Asai T., Andersen T.B., Nunome H., and Sterzing T.(2010): The biomechanics of kicking in soccer: a review. Journal of Sports Sciences; 28(8): 805-817.

39. Lees A., and Davies T.(1988): The effects of fatigue on soccer kick biomechanics(abstract). Journal of Sports Sciences, 8:156-157.

40. Lees A., and Nolan L. (1998): The biomechanics of soccer: a review. Journal of Sports Sciences; 16:211-234.

41. Levanon J,. and Dapena J.(1998): Comparison of the kinematics of the full-instep and pass kicks in soccer. Medicine and Science in sports and Exercise, 30: 917-927.

42. Marino W., and Drouin D. (2000): Effect of fatigue on forward, maximum velocity in ICE hockey skating. International Symposium on Biomechanics in Sports.

43. Massoumi F., and Shahbazi M. (2006): A new biomechanical approach to side-foot soccer shots characteristics determination. International Symposium on Biomechanics in Sports.

44. Masuda K., Kikuhara N., Demura S., Katsuta S., and Yamanaka K.(2005): Relationship between muscle strength in various isokinetic movements and kick performance among soccer players. J Sports Med Phys Fitness, 45(1):44-52.

45. Matt G.(2009): The influence of soccerspecific activity on the kinematics of an agility sprint, European Journal of Sport Science, $9 ;(1): 23-33$.

46. Meamarbashi A., and Hossaini R.(2010): Application of novel inertial technique to 
compare the kineatics and kinetics of the legs in the soccer instep kick. Journal of Human Kinetics, 23:3-12.

47. Misuta M,. Menezes R., Moura F., Figueroa P., Cunha S., and Barros R.(2006): Covered distances analysis of Brazilian professional soccer players obtained by an automatic tracking method. International Symposium on Biomechanics in Sports.

48. Mohammad A., Riyajuddin and Javed K.(2011): A Kinematic study of instep soccer kick at contact phase. International Journal of Sports Sciences \& Fitness, 1;(2):Abstract.

49. Mohr M., Krustrup P., and Bangsbo j. (2003): Match performance of high-standard soccer players with special reference to development of fatigue. Journal of Sports sciences;(21)7:519-528.

50. Mohr M., Krustrup P., and Bangsbo j.(2005): Fatigue in soccer: A brief review. Journal of Sports sciences;(23)6:593-599.

51. Nunome H., Asai T., Ikegami Y., and Sakurai S.(2002): Three-dimensional kinetic analysis of side-foot and instep soccer kicks. Medicine and Science in Sports and Exercise, 34: 2028-2036.

52. Nunome H., Shinkai H., and Ikegami Y.(2012): Ball impact kinematics and dynamics in soccer kicking. 30th Annual Conference of Biomechanics in Sports, 35-42.

53. Pain M., and Harwood C.(2007): The performance environment of the England youth soccer teams. Journal of Sports Sciences; 25(12): 1307-1324.

54. Pilar S., and David L.(2011): Analysis of corner kicks in relation to match status in the 2006 world cup. European Journal of Sport Science, 12;(2):121-129.

55. Prassas S., Terauds J., and Nathan T.(1990): Three-dimensional kinematic analysis of high and low trajectory kicks in soccer. International Conference on Biomechanics in Sports, 145149.

56. Rahnama N., Reilly T., Lees A., and Smith P.(2003): Muscle fatigue induced by exercise simulating the work rate of competitive soccer. Journal of Sports Sciences;(21): 11:933-942.
57. Rampinini E., Impellozzeri F., Castagna C., Coutts A., and Wisloff U.(2008): Technical performance during soccer matches of the Italian Serie a league: effect of fatigue and competitive level. J Sci Med Sport, 12(1); 227233.

58. Reilly, T.(1996a). Fitness assessment. In Science and Soccer (ed. Reilly, T.), pp. 25-50. London: E \& FN Spon.

59. Reilly T.(1996b): Biomechanics and soccer medicine. In: Reilly $T$, editor. Science and Soccer. London: E\&FN Spon, 123-134.

60. Reilly T.(1997): Energetics of high-intensity exercise (soccer) with particular reference to fatigue; Journal of Sports sciences;(15)3:257263.

61. Reilly T., Drust B., and Clarke N.(2006): Muscle fatigue during football match-play. Sports Med, 38;(5):357-367.

62. Reilly T., and Korkusuz F.(2009): Science and Football VI. Science and Football VI: The Proceedings of the Sixth World Congress on Science and Football (v. 6).

63. Robert B., Sherry I., Brian P., Stephen L., and Riley W.(2007): Lower extremity muscle activation and alignment during the soccer instep and side-foot kicks. Journal of Orthopaedic \& Sports Physical Therapy, 37;(5):260-268.

64. Rodacki A., Fowler N., and Bennett S. (2002): Vertical jump coordination: fatigue effects. Medicine \& Science in Sports \& Exercise; 24:105-116.

65. Rodacki A., Fowler N., Simon J., and Bennett S. (2001): Multi-segment coordination: effect fatigue. Medicine \& Science in Sports \& Exercise; 33(7):1157-1167.

66. Sardinha L., and Zebas C. (1986): The effect of perceived fatigue on volleyball spike skill performance. International Symposium on Biomechanics in Sports; 4:249-255.

67. Sasa B.,Ratko S., Sasa J., Radoslav B., Stanimir J., Goran K., and Pavlos E.(2010): Kinematics of accurate inside of foot kick. Kinesiololgia Slovenica, 16;(1-2): 75-83.

68. Scurr J., and Hall B.(2009): The Effects of approach angle on penalty kicking accuracy and kick kinematics with recreational soccer 
players. Journal of Sports Science and Medicine, 8:230-234.

69. Shan G., and Zhang X.(2011): From 2D leg kinematics to 3D full-body biomechanics-the past, present and future of scientific analysis of maximal instep kick in soccer, Sports Medicine Arthroscopy Rehabilitation Therapy Technology, 3;(23): 1-10.

70. Smith J., Ball K., and Macmahon C.(2009): Foot-to-ball interaction in preferred and nonpreferred leg Australian rules kicking. International Symposium on Biomechanics in Sports.

71. Sterzing T.(2010): Kicking in soccer. International Symposium on Biomechanics in Sports, 42-45.

72. Sterzing T., Lange J., Wachtler T., Muller C., and Milani T.(2009): Velocity and accuracy as performance criteria for three different soccer kicking techniques. International Conference on Biomechanics in Sports, 27.

73. Stolen T., Chamari K., Castagna C., and Wisbff U.(2005): Physiology of soccer an update. Sports Med;35(6):501-536.
74. Stone K., and Oliver J.(2009): The effect of 45 minutes of soccer-specific exercise on the performance of soccer skills. Int $\mathbf{J}$ Sports Physiol Perform, 4(2): 163-175.

75. Teshima T., Hosoda M., Matsuzaki Y., and Tsunoda N.(2008): Effect of swing velocity on ball kicking performances in young male soccer players. 13th annual ECSS Congress Estoril/ Portugal.

76. Uygur M., Moktepe A., AK E., Karabrk H., and Korkusuz F.(2010): The effect of fatigue on the kinematics of ferr throw shooting in basketball. Journal of human kinetics, 24:51-56.

77. Veale J., Pearce A., and Carlson J. (2007): Player movement patterns in an elite junior Australian rules football team: an exploratory study. Journal of Sports Science and Medicine; 6:254-260.

78. Weston W., Heidi O., and Meredith R. (2008): Effects of fatigue on the plant leg EMG during an instep soccer kick. Medicine \& Science in Sports \& Exercise; 40(5):216. 